\title{
A review of ambient nanoparticles (PM0.1) in South East Asian cities: biomass and fossil burning impacts
}

Worradorn Phairuang ${ }^{1,2^{*}}$, Muanfun Inerb ${ }^{3}$, Mitsuhiko Hata ${ }^{2}$ and Masami Furuuchi ${ }^{2,3}$

${ }^{1}$ Department of Geography, Faculty of Social Sciences, Chiang Mai University, Muang, Chiang Mai, 50200 Thailand

${ }^{2}$ Faculty of Geoscience and Civil Engineering, Institute of Science and Engineering, Kanazawa University, Kakuma-machi, Kanazawa, Ishikawa, 920-1192 Japan

${ }^{3}$ Faculty of Environmental Management, Prince of Songkla University, Hat Yai, Songkhla, 90112 Thailand

*Correspondence e-mail: worradorn.ph@cmu.ac.th; worradorn@gmail.com

Table of Contents

Abstract

1. Introduction

2. $\mathrm{PM}_{0.1}$ mass concentration in South East Asia atmosphere

3. Sources and characteristics of $\mathrm{PM}_{0.1}$ in South East Asia

4. Health concerns of $\mathrm{PM}_{0.1}$ in South East Asia

5. Challenges study of $\mathrm{PM}_{0.1}$ in South East Asia

6. Summary and Recommendation

7. Reference 
Abstract: $\mathrm{PM}_{0.1}$ (particles diameter $\leq 0.1 \mu \mathrm{m}$ ), nanoparticles (NPs), and ultrafine particles (UFPs), were interchangeably used in the scientific communities. $\mathrm{PM}_{0.1}$ originated from both natural and human sources. However, investigations of $\mathrm{PM}_{0.1}$ and its effects on the environment, visibility, and human health risk to understand the levels of air pollution, sources, and impacts in South East Asia (SEA) countries continue to be lacking. The concentration of $\mathrm{PM}_{0.1}$ in most SEA countries are much worse than those in western countries environment. A further motivation of this reviewed article is to provide a critical synthesis of the current knowledge and study of ambient $\mathrm{PM}_{0.1}$ in SEA cities. The main influence of characteristics of $\mathrm{PM}_{0.1}$ appears to be local sources including biomass burning and motor vehicles. Continuous monitoring of $\mathrm{PM}_{0.1}$ in terms of both mass and number concentration should be further understood. A critical review is of great importance to facilitating air pollution control policies and predicting the behavior of $\mathrm{PM}_{0.1}$ in SEA.

Keywords; Health Risk, Ultrafine Particles, Nanoparticles, South East Asia, Biomass burning

\section{Introduction}

Particulate matters (PM) have a complex component, including acids (such as nitrates and sulfates), organic chemicals, and heavy metals, some of these components have a hazard for human health [1]. Especially, smaller particles down to nano-size range mainly come from human sources, contain extremely hazardous components like heavy metals, carbon components, and polycyclic aromatic hydrocarbons (PAHs) [2]. PM had a wide range of particle size and can be categorized into three modes: coarse particles $\left(\mathrm{PM}_{10-2.5}\right.$; aerodynamic diameter between 2.5 and $10 \mu \mathrm{m})$, fine particles $\left(\mathrm{PM}_{2.5}\right.$; predominantly in accumulation mode, aerodynamic diameter 
range from 0 to $2.5 \mu \mathrm{m})$, and ultrafine particles $\left(\mathrm{PM}_{0.1}\right.$; nucleation mode, aerodynamic diameter smaller than $0.1 \mu \mathrm{m}$, or $100 \mathrm{~nm}$ ) [1-2]. PM0.1, ultrafine particles (UFPs), and nanoparticles (NPs) are interchangeably used in scientific society [3]. NPs are commonly used in representing particles from engineer-material that release to the environment. At the same time, other researcher groups use different names. For instance, toxicologists typically use ultrafine, fine, and coarse modes, and monitoring organizations i.e., the United States Environmental Protection Agency (US.EPA) uses $\mathrm{PM}_{0.1}, \mathrm{PM}_{1}, \mathrm{PM}_{2.5}$, and $\mathrm{PM}_{10}$ refer the atmospheric particulate matter [4]. In the recent decade, it has been found that $\mathrm{PM}_{0.1}$ poses the most risks to human health effects [56]. It is not enough information on the status and characteristics of atmospheric $\mathrm{PM}_{0.1}$, and their emission sources remain incomplete currently. Because $\mathrm{PM}_{0.1}$ is challenging to study due to its tiny sizes, high chemical reactivity, and rapid changes [6-7].

The data on physical, optical, and chemical characteristics in $\mathrm{PM}_{0.1}$ are scarce worldwide including all South-East Asian (SEA) countries, where in the past decades have been the dominant contributors of PMs into the atmosphere [8-11]. Several research publications have been investigated the size distribution of atmospheric particles bounded chemicals in various countries around SEA due to environmental damage and health effects. [10-11]. Atmospheric PMs in SEA countries are presently based on the concentrations of $\mathrm{PM}_{10}$ and $\mathrm{PM}_{2.5}$ as well as to a slight area on $\mathrm{PM}_{1}$ (sub-micron particle) [10, 12-13]. Several studies based on satellite remote sensing, ground-based observing, and mathematical modeling techniques revealed that aerosol plume during smoke-haze exceeded the national standard of SEA countries, which has a very high value compared to the World Health Organization (WHO) or other countries standard [14]. A recent study in Thailand and neighboring countries displayed that $\mathrm{PM}_{0.1}$ represented approximately $10-15 \%$ of total suspended particulates (TSP) in ambient air [11, 15-17]. 
The status and characteristics of ambient $\mathrm{PM}_{0.1}$ have not been compared between different locations. In addition, the other chemical compositions in $\mathrm{PM}_{0.1}$ are so far poorly studied in Asia. All these available data from $\mathrm{PM}_{0.1}$ in western countries i.e., Europe and the United States of America (USA), are more progressive [18-20]. However, the data in SEA city environments are still separate in detail. Consequently, the motivation of this review is to recognize the recent data, sources, and knowledge gap in $\mathrm{PM}_{0.1}$ emission and exposure levels. The authors discuss the recent situation of $\mathrm{PM}_{0.1}$ study in Asian developing countries in a case study of SEA to better understanding and future perspective of ambient $\mathrm{PM}_{0.1}$. This review collects the recent research papers on all aspect of PMs in SEA. Over 100 peer-reviewed journals in Scopus and ISI database was used to analyze and integrate to synthesis and group in this paper. The term and keywords was used to search including "PM $\mathrm{P}_{0.1}$, biomass burning, ultrafine particles, haze pollution, health effects, emission inventory, and clean air policies. The synthesis reviewed article prefers to use the recent publish in 6 years from 2016 - 2021.

\section{PMo.1 mass concentration in South East Asia atmosphere}

The PMs are separated into three modes according to particle size, i.e., coarse, fine, and ultrafine modes [21]. The ultrafine $\left(\mathrm{PM}_{0.1}\right)$ fractions in the ambient particulate matter $(\mathrm{PM})$ have a very low particle mass concentration but a huge number of particles [7]. Most particles by numbers lie below $0.1 \mu \mathrm{m}(100 \mathrm{~nm})$ and there are in $\mathrm{PM}_{0.1}$. However, their concentration in terms of mass per volume is very low. No standards for ambient $\mathrm{PM}_{0.1}$ or UFPs have been adopted in Asian countries. The European Committee for standardization announced that Condensation Particle Counter (CPC) is a standard protocol to measure ambient UFPs [22]. However, only the emission standard for diesel and gasoline-direct injection engine road vehicles 
must meet a type-approval of UFPs for non-volatiles particles of $>23 \mathrm{~nm}$ diameter (The Solid Particle Number $>23 \mathrm{~nm}$ method; SPN23) [23]. According to a very small amount and mass concentration, the most widely used to measure UFPs is particle number concentration (PNC). The estimated concentration based on $10 \mu \mathrm{g} / \mathrm{m}^{3}$ in $\mathrm{PM}_{2.5}$ found that $\mathrm{PM}_{2.5} 1$ particle/cm ${ }^{3}$ equal to $\mathrm{PM}_{0.02}(<20 \mathrm{~nm}) 2.4 \times 10^{6}$ particle $/ \mathrm{cm}^{3}$, or $\mathrm{PM}_{10} 1$ particle $/ \mathrm{cm}^{3}$ similar to UFPs $1.0 \times 10^{6}$ particle $/ \mathrm{cm}^{3}[6,24]$. The number concentration and surface area are suitable to measure UPFs small amount of mass concentration in the past decades $[2,6]$.

The average $\mathrm{PM}_{0.1}$ mass concentration in SEA is progressive in the past decade (Table 1). The preliminary study of ambient $\mathrm{PM}_{0.1}$ in SEA and publish in an international peer-review journal is based on a study in Thailand during 2014-2105 [11]. The $\mathrm{PM}_{0.1}$ mass concentration in Bangkok and Chiang Mai, Thailand be $14.80 \pm 1.99$ and $25.21 \pm 4.73 \mu \mathrm{g} / \mathrm{m}^{3}$, respectively. Bangkok is a capital city in Thailand and one of the densest populated cities in Asia. The high episode in $\mathrm{PM}_{0.1}$ particles in Chiang Mai is recognized to arise from open biomass fires in the dry season (Jan-May). In Thailand, $\mathrm{PM}_{0.1}$ concentration in Pathumtani, one of the Bangkok Metropolitan Region (BMR) areas, is also elevated mass concentration in both wet and dry seasons [15]. In another study in Hat Yai, southern Thailand [16], $\mathrm{PM}_{0.1}$ was $10.17 \pm 2.23 \mu \mathrm{g} / \mathrm{m}^{3}$ representing PM concentrations lower than other parts of Thailand. Moreover, as Zhao et al. (2016) [25] reported, compare $\mathrm{PM}_{0.1}$ concentration during the dry season (Mar-Apr 2016) in many cities, including Chiang Mai, Bangkok, Songkhla, Riau, Ho Chi Minh City, Phnom Penh, Kuala Lumpur. The study found that mass concentration $\left(\mu \mathrm{g} / \mathrm{m}^{3}\right)$ decreased in the order, Phnom Penh (18.9) > Chiang Mai (16.5) > Hanoi (15.4) > Ho Chi Minh City (13.1) > Riau (12.4) > North Bangkok (11.9) > Hat Yai (10.9) > Kuala Lumpur (9.3) > Bangkok (7.7). The higher mass concentration in Upper SEA countries than lower SEA countries due to the dry season during 
that period that the open biomass burning has been reported by several researchers [26-27]. PMs concentrations were increased every dry season (February-April) which start to increase at around the beginning of February and reached its peak in March before decreasing by mid-April [11]. The main emission source of PMs worsening during the dry season in these areas was identified as open biomass burning including forest fire and crop residue burning [15, 27]. The above mentioned corresponded with the accumulated number of fire hotspots location that was high in the dry season and low in the wet season. Each hotspot/active fire location represents the center of approximately $1 \mathrm{~km}$ pixel flagged as containing one or more actively burning hotspots/fires within that pixel [10]. Generally, $\mathrm{PM}_{0.1}$ was a key identifier of diesel exhaust and it was sensitive to open biomass burning in this area [11].

Moreover, ambient $\mathrm{PM}_{0.1}$ in Vietnam and Indonesia is very progressive. In Indonesia, the study by Amin et al. (2019) and Putri et al. (2021) [28-29] suggested that the PM0.1 mass concentration in the dry season is higher than the wet season in all monitoring sites. In addition, the mass concentrations by different monitoring sites have a concentration as follows, urban > suburban > rural. In Vietnam, many studies of $\mathrm{PM}_{0.1}$ in Hanoi, the capital city in Vietnam, are more progressive than other SEA cities [17, 30-34]. The results show that various mass concentrations in different environments in Hanoi ranged from 1 to $17 \mu \mathrm{g} / \mathrm{m}^{3}$.

Table 1 Mass concentration of $\mathrm{PM}_{0.1}$ at difference locations in Asian Environment

\begin{tabular}{|c|c|c|c|}
\hline Location & Site description & Period & Concentration $\left(\mu \mathrm{g} / \mathrm{m}^{3}\right)$ \\
\hline \multirow{2}{*}{ Pathumtani, Thailand } & Suburban & Oct 2019 & $13.47 \pm 0.79$ \\
\hline & Suburban & Jan-Feb 2020 & $18.88 \pm 3.99$ \\
\hline Hat Yai, Thailand & Mixed & Jan-Dec 2018 & $10.17 \pm 2.23$ \\
\hline Hat Yai, Thailand & Mixed & Mar-April 2016 & 10.9 \\
\hline
\end{tabular}




\begin{tabular}{|c|c|c|c|}
\hline North Bangkok, Thailand & Urban-traffic & Jul 2014 - Jun 2015 & $14.80 \pm 1.99$ \\
\hline North Bangkok, Thailand & Urban-traffic & Mar-April 2016 & 11.9 \\
\hline Bangkok, Thailand & Urban-traffic & Mar-April 2016 & 7.7 \\
\hline Chiang Mai, Thailand & Suburban & Sep 2014 - Jun 2015 & $25.21 \pm 4.73$ \\
\hline Chiang Mai, Thailand & Suburban & Mar-April 2016 & 16.5 \\
\hline Riau, Indonesia & Urban & Mar-April 2016 & 12.4 \\
\hline \multirow{4}{*}{ North Sumatra, Indonesia } & Urban-traffic & Feb 2019 & $13.10 \pm 3.80$ \\
\hline & Rural-volcano & Mar 2019 & $7.10 \pm 2.50$ \\
\hline & Industry Area & Feb-Mar 2019 & $16.80 \pm 4.00$ \\
\hline & School Environment & Feb 2019 & $15.90 \pm 1.60$ \\
\hline \multirow{2}{*}{ Padang, Indonesia } & \multirow{2}{*}{ Rural } & Mar 2018 & 5.36 \\
\hline & & Aug 2018 & 5.57 \\
\hline \multirow{2}{*}{ Muaro Jambi, Indonesia } & \multirow{2}{*}{ Suburban } & Mar 2018 & 9.20 \\
\hline & & Aug 2018 & 9.61 \\
\hline \multirow{2}{*}{ Pekanbaru, Indonesia } & \multirow{2}{*}{ Urban } & Mar 2018 & 10.92 \\
\hline & & Aug 2018 & 15.16 \\
\hline \multirow{2}{*}{ Hanoi, Vietnam } & Mixed & Aug-Dec 2015 & $5.36-5.79$ \\
\hline & Urban-traffic & Aug-Dec 2015 & $6.06-11.90$ \\
\hline Hanoi, Vietnam & Mixed & Nov-Dec 2015 & $5.44 \pm 2.03$ \\
\hline \multirow{2}{*}{ Hanoi, Vietnam } & Mixed & Jul-Aug 2015 & $1.47 \pm 0.54$ \\
\hline & Mixed & Mar 2016 & $1.71 \pm 0.61$ \\
\hline Hanoi, Vietnam & Mixed & Mar-April 2016 & 15.4 \\
\hline \multirow{2}{*}{ Hanoi, Vietnam } & \multirow{2}{*}{ Residential Area } & Jan 2019 & 8.74 \\
\hline & & Apr-May 2019 & 5.28 \\
\hline \multirow{2}{*}{ Hanoi, Vietnam } & Suburban 1 (Rice burning) & Nov 2019 & $6.50 \pm 2.20$ \\
\hline & Suburban 2 (Rice burning) & Nov 2019 & $11.50 \pm 3.90$ \\
\hline \multirow[t]{2}{*}{ Hanoi, Vietnam } & School Environment & Nov 2019 - Jan 2020 & $17.07 \pm 3.70$ \\
\hline & Urban-traffic & Mar-April 2016 & 13.1 \\
\hline Phnom Penh, Cambodia & Urban & Mar-April 2016 & 18.9 \\
\hline Kuala Lumpur, Malaysia & Suburban & Mar-April 2016 & 9.3 \\
\hline
\end{tabular}


Instead, the mass concentrations are very low in western countries. Venecek et al. (2019) [19] studied regional $\mathrm{PM}_{0.1}$ concentrations in 39 cities across the USA and found that $\mathrm{PM}_{0.1}$ levels exceed $2 \mu \mathrm{g} / \mathrm{m}^{3}$ during summer pollution episodes. Conversely, the annual average mass concentration of $\mathrm{PM}_{0.1}$ is very low, below $1 \mu \mathrm{g} / \mathrm{m}^{3}$. Moreover, the United Kingdom (UK) described that the mass concentration of $\mathrm{PM}_{0.1}$ based on the estimated fraction of $\mathrm{PM}_{10}$ in each emission source is as follows; production process, non-road transportations, agriculture, industrial off-road mobile machinery, transformation industries, energy combustion, combustion in industries as well as waste incineration $(15 \%, 14 \%, 9 \%, 9 \%, 8 \%, 7 \%$ and $4 \%$, respectively) [35]. $\mathrm{PM}_{0.1}$ are mostly measured in terms of particle number concentrations (PNC) due to the very low mass concentrations in all cities around the western part of the world [18].

\section{Sources and Characteristics of PM0.1 in South East Asia}

Regarding the natural sources, primary $\mathrm{PM}_{0.1}$ is mainly generated by forest fires, while lesser fractions come from maritime aerosols and volcanic eruptions [2]. On the other hand, anthropogenic sources of $\mathrm{PM}_{0.1}$ include transportation (on- and off-road vehicles, diesel engines, airplanes, and shipping), industrial combustion processes including biomass burning and waste incineration, cigarette smoking, and meat cooking [6]. Therefore, the main emission sources of $\mathrm{PM}_{0.1}$ are both natural and anthropogenic sources. Figure 1. shows the morphology of atmospheric nanoparticles from Chiang Mai, Thailand, as observed in the scanning electron microscope (SEM) analysis. 


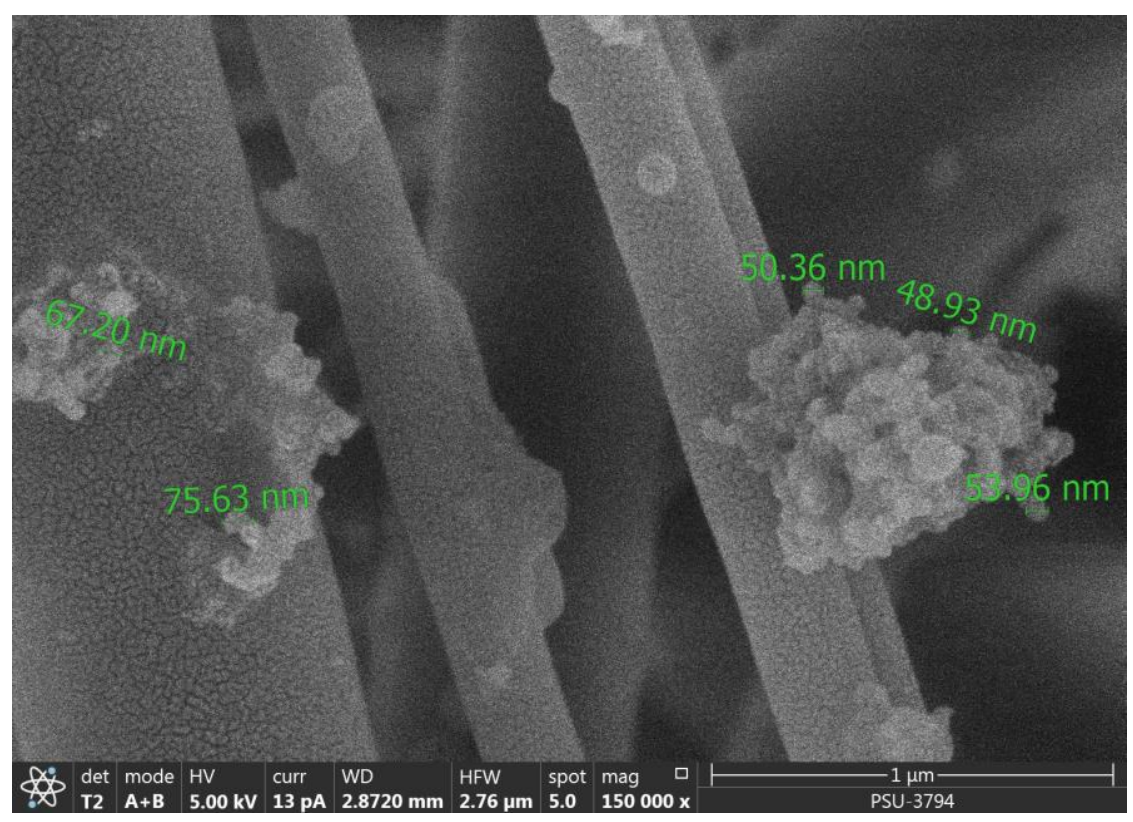

Figure 1. SEM images of atmospheric nanoparticles from Chiang Mai, Thailand, year 2015 (forest fires dominated as emission sources during the dry season)

Most studies of the primary emission source of $\mathrm{PM}_{0.1}$ in Asia are related to road vehicles [36-38]. In an urban area, traffic is the major source of $\mathrm{PM}_{0.1}$ emissions. Diesel engines dominate $\mathrm{PM}_{0.1}$ in mega-cities, including Shanghai, China [39], Hanoi, Vietnam [17] and Bangkok, Thailand [11]. Diesel engines have an emission factor about two times of magnitude higher than gasoline engines [40]. On the other hand, as Kumar et al. (2013) [5], the forest fires emitted particles dominate over traffic emissions, and the size distribution peaks at approximately 120 nm for a fresh aerosol plume. In addition, the recent study by Phairuang et al. (2019a) [11] states that open biomass burning in central and northern Thailand dominated the release of carbon materials into the atmosphere. The $\mathrm{PM}_{0.1}$ particles, primarily derived from motor vehicle emissions, are also strongly affected by open biomass burning in the upper part of Thailand. Hence this activity is a significant factor affecting air quality during the dry season. Similarly, ambient $\mathrm{PM}_{0.1}$ study in Hanoi, Vietnam, showed that high mass concentrations of $\mathrm{PM}_{0.1}$ were 
detected during rice straw burning periods [17]. However, some possibly important sources, such as domestic wood burning, are poorly quantified in Asian countries [41-42].

The chemical composition study in NPs is still limited, especially in ambient $\mathrm{PM}_{0.1}$ particles. However, there have been a few publications from sources related to NPs and chemical composition. For instance, polycyclic aromatic hydrocarbons (PAHs) dominate PM sources' emission components [41, 43-44]. Most PAHs emissions are generated from incomplete combustion of natural and human sources, including vehicle exhaust, biomass burning, industrial activities, and coal combustion. Hata et al. (2014) [41] studied the characteristics of NPs emitted from biomass fuels burning in Asia. The result displayed that approximately $30 \%$ of the biomass fuels burning smoke had a mass down to a range of $<100 \mathrm{~nm}$. Additionally, PM smaller than $0.43 \mu \mathrm{m}$ significantly contributed to their toxicity of PAHs and the fraction of Water-soluble Organic Carbon (WSOC). In the same manner, Chomanee et al. (2018) [42] studied the PAHs in smoke particles released from the fuelwood (para-rubber) combustion. This result displays that the ultrafine $\left(\mathrm{PM}_{0.07}\right)$ smoke particles comprised the highest number of PAHs and Benzo[a]pyrene-Toxic Equivalence Quotient (BaP-TEQ). The major fraction of NPs had the largest emission of toxicity per unit PM mass comparing to fine and coarse PM. In addition, the recent study during the biomass open burning episode in western Thailand suggested that Toxicity equivalent (BaP-TEQ) and the mutagenic equivalent (MEQ-BaP) concentrations during the biomass open burning episode were considerably higher than those in the non-smoke episode in $\mathrm{PM}_{2.5}$ [45]. This is an important point to concentrated on smaller particles, especially NPs on any emission sources due to a lack of reliable information on the sources and magnitudes in Asian countries. 
Secondary $\mathrm{PM}_{0.1}$ aerosols are mainly generated from atmospheric photochemical of gaseous precursors and by condensation of semi-volatile vapors [46]. Such new particle formation can occur during low relative humidity and wind speed at low pre-existing particle surface area and high global radiation [47]. Reche et al. (2011) [48], described that new particle formation in an urban area in Europe during warmer and sunny climates as an important contributor to air pollution. In SEA, Thuy et al. (2018) [17] stated that Secondary Organic Carbon (SOC) is more dominant in smaller particles than in larger particles; and the SOC in $\mathrm{PM}_{0.1}$ contributes up to $42.7 \%$ of the OC level in Hanoi, Vietnam. The secondary atmospheric $\mathrm{PM}_{0.1}$ in the Asian environment remains poorly understood.

\section{Health concerns of PMo.1}

$\mathrm{PM}_{0.1}$ has strongly believed very high toxic properties, because there has a high surface area that can absorb many poisonous substances. After they penetrate the human organ systems, allowing translocation and interactions to a human body organ and highly potential deeply into circular systems via respiratory mechanism [49-51]. The World Health Organization (WHO, 2013) [52] suggested that the epidemiological data of $\mathrm{PM}_{0.1}$ are very too scarce to estimate or to use as a policy-making for air quality control management of $\mathrm{PM}_{0.1}$. The Health Effects Institute (HEI, 2013) [53] reflected that the ongoing evidence did not convincingly support the suggestion that $\mathrm{PM}_{0.1}$ alone can account for important conducts for the adverse effects that have been associated with atmospheric pollutants such as $\mathrm{PM}_{2.5}$ and $\mathrm{PM}_{10}$ [54-55].

In health risk assessment, toxicity equivalent concentration (TEQs), calculations based on toxic equivalent factors (TEFs), can be used to estimate health risks associated with PAHs [56]. High concentrations of PMs containing PAH's are well-known to consequence in symptoms, i.e., 
eye irritation, diarrhea, vomiting, and nausea [56-57]. The detrimental effects of PAHs hang on the mechanism of exposure. Benzo[a]pyrene $(\mathrm{BaP})$ is the well-known PAH to cause cancer on a laboratory scale resulting long term exposure [57]. The BaP-TEQ is a widely used indicator to estimate the exposure to PAHs to human health [42]. On the other hand, there have been limited studies on the characteristics of $\mathrm{PM}_{0.1}$ and toxic PAHs in the Asian environment. Moreover, it is vital to note, that finer particles are a more significant source of carcinogenic properties and cause more human health consequences than larger particles due to their higher surface area that can absorb many toxic elements.

Guan et al. (2016) [58] studied in China, they found that increasing $10 \mu \mathrm{g} / \mathrm{m}^{3}$ in $\mathrm{PM}_{2.5}$ from any emission sources have been linked to a $3.1 \%$ increase in the risk of hospitalization as well as a $2.5 \%$ rise in mortality. Crippa et al. (2016) [59], reported the short-term exposure to agricultural residue burning and peat-land fires in heavy haze episodes in 2015 from Indonesia might have caused 11,880 excess mortalities. The studies have stated the adverse effect of inhaled atmospheric $\mathrm{PM}_{0.1}$ on human health to continue lacking in SEA. Three are still limited information between $\mathrm{PM}_{0.1}$ and disease. However, there have not become fully aware of the critical hazardous of $\mathrm{PM}_{0.1}$ in the air pollution on human health [2-4].

\section{Challenges study in PMo.1}

1. $\quad 5.1$ Evaluation of $\mathrm{PM}_{0.1}$

2. The present status and characteristics, comparison between cities and countries need assessments of events and long-range transportation. For instance, Southeast Asia (SEA) has been a source of PM pollutants affecting countries within and outside this region [60]. The transport of plumes from Indonesian forest fires affects Singapore, Malaysia, Brunei, and 
southern Thailand [16, 61]. United States Environmental Protection Agency (US-EPA) has mentioned that PM is one of the criteria pollutants that is the most widespread health threat. PM is the generic term used for these types of air pollutants, consisting of complex mixtures of solid or liquid droplets or both suspended in the breathing air, which vary in size and composition [62]. According to the criteria of particle size, most SEA countries had been designated that $\mathrm{PM}_{2.5}$ was a criteria pollutant. However, $\mathrm{PM}_{0.1}$ is more concerned about health impact than larger PM sizes. Accordingly, the sources, abundance, chemical compositions and migration of $\mathrm{PM}_{0.1}$ between regions and countries need further studies.

3. $\quad 5.2$ Information on $\mathrm{PM}_{0.1}$ emission sources

The Emission Inventory (EI) of $\mathrm{PM}_{0.1}$ is subject to very high mass and particle number emission uncertainties. There are very scarce emission factors (EFs) of methodologies for estimating $\mathrm{PM}_{0.1}$ emissions in available official EI guidebooks. EFs on $\mathrm{PM}_{0.1}$ number, mass, a mass of chemicals should be studied in more detail. Samae et al. (2021, 2022) [63-64] reported the first EFs from solid biomass combustion in Thailand including 11 types of biomass (Avicennia alba Blume, Xylocarpus moluccensis, Rhizophora mucronata, bagasse, sugarcane leaves, corn residue, rice straw, rice stubble, palm fiber, palm kernel, and rubberwood). The $\mathrm{PM}_{0.1}$ mass concentration is very low, approximately $1-8 \%$ of total PM. Emission factors of particle size $<0.1 \mu \mathrm{m}$ were in the range of $0.11-0.28 \mathrm{~g} \mathrm{~kg}^{-1}$. There is not complete EI of PM0.1 in Asia due to a lack of information on EFs and other parameters [11,65]. Knowledge of the EFs of $\mathrm{PM}_{0.1}$ is fundamental to the development of strategies for pollution control and air quality management.

5.3 Development and application of new $\mathrm{PM}_{0.1}$ tools 
5.3.1 Measurements of atmospheric particles are inherently more complex than other gases-phase pollutants. The new technology to size-classified PMs down to $\mathrm{PM}_{0.1}$ is also vital to study the physical and chemical characteristics of ambient $\mathrm{PM}_{0.1}$ [66-67]. For example, the inertial filter (IF) technology to collect various size fractions, including nano-particles, in a short sampling period will be important to gather the ambient $\mathrm{PM}_{0.1}[68-71]$. The artifacts due to the evaporation of semi-volatiles should be much smaller than those of conventional types of nanoparticle samplers, e.g., low-pressure impactors and Nano-MOUDI [72-73].

5.3.2 A High-Volume $\mathrm{PM}_{0.1}$ air sampler for toxicity evaluation will be able to evaluate dynamic health risks. Retention or removal of semi-volatile particles for $\mathrm{PM}_{0.1}$ can be volatilized within the sampling system, because of their large specific surface area. Considering $\mathrm{PM}_{0.1}$ related to chemical compositions with minimal artifacts during air sampling caused by the degradable characteristics of chemicals and semi-volatile is also a crucially important issue [74]. The High-Volume $\mathrm{PM}_{0.1}$ will improve the $\mathrm{PM}_{0.1}$ instrument toward 1) understanding ambient $\mathrm{PM}_{0.1}$ based on various chemicals in $\mathrm{PM}_{0.1}$ collected with high time resolution, 2) risk assessment using a large amount of $\mathrm{PM}_{0.1}$ collected by the tool [75]. Hence, there is a need for tools to collect more significant amounts of $\mathrm{PM}_{0.1}$ in a short period with minimal artifacts.

5.3.3 The $\mathrm{PM}_{0.1}$ real-time sensors in the internet of things (IoT) monitoring network (big data) will play an important role in understanding the $\mathrm{PM}_{0.1}$ plume migration and transportation, with temporal variations by geo-specific location [76-77]. The real-time and IoT sensor for PMs monitoring has been a vital tool, potentially becoming an integral part of air quality monitoring and management, especially during the haze episode of intensive biomass burning smoke in the Asian environment [78].

5.4 Summarizing facts on $\mathrm{PM}_{0.1}$ for policy-making 
Future research on $\mathrm{PM}_{0.1}$ needs to focus on intervention, classification, and quantification of mass and number concentrations with mixed emission sources at ambient and personal levels to detrimental human health effects. The environmental quality standard regarding $\mathrm{PM}_{0.1}$ in Asian countries is only focused on mass concentrations. The future precise study particle types and size govern $\mathrm{PM}_{0.1}$ will fulfill the research gaps, perspectives and emerging challenges for $\mathrm{PM}_{0.1}$ policymaking in Asia.

\section{Conclusion}

Future studies on atmospheric nanoparticles in Asia should focus on the abundance, sources, distribution and temporal and spatial variations of $\mathrm{PM}_{0.1}$ in urban and rural Asian environments. The exposure to $\mathrm{PM}_{0.1}$ should be quantified to understand the exposure of nanosize particles in humans. Continuous monitoring of $\mathrm{PM}_{0.1}$ in terms of both mass and number concentration should be further understood. Future research on $\mathrm{PM}_{0.1}$ needs to focus on the identification and quantification of $\mathrm{PM}_{0.1}$ particles. Finally, better knowledge about the physicochemical characteristics of $\mathrm{PM}_{0.1}$ generated by various emission sources in the Asian environment will help fill the gap about air quality policies and management in this region.

\section{Acknowledgement}

This work was financially supported by Office of the Permanent Secretary, Ministry of Higher Education, Science, Research and Innovation (Grant No. RGNS 63-253). Moreover, this work was partially supported by JSPS KAKENHI Grant Number JP19K12369 in Japan. Additionally, the authors also wish to thank Dr. Milton S. Feather for improving English in this manuscript. 


\section{Conflict of interest}

The authors declare no conflict of interest.

\section{References}

1. Buseck, P.R.; Adachi, K. Nanoparticles in the atmosphere. Elements 2008, 4(6), 389394.

2. Schraufnagel, D.E. The health effects of ultrafine particles. Experimental \& molecular medicine 2020, 52(3), 311-317.

3. Slezakova, K.; Morais, S.; do Carmo Pereira, M. Atmospheric nanoparticles and their impacts on public health. In Current topics in public health. IntechOpen. 2013

4. Oberdörster, G.; Oberdörster, E.; Oberdörster, J. Nanotoxicology: an emerging discipline evolving from studies of ultrafine particles. Environmental Health Perspectives 2005 113(7), 823-839.

5. Kumar, P.; Pirjola, L.; Ketzel, M.; Harrison, R.M. Nanoparticle emissions from 11 nonvehicle exhaust sources-a review. Atmospheric Environment 2013, 67, 252-277.

6. Kwon, H.S.; Ryu, M.H.; Carlsten, C. Ultrafine particles: unique physicochemical properties relevant to health and disease. Experimental \& molecular medicine $\mathbf{2 0 2 0}$, 52(3), 318-328.

7. Terzano, C.; Di Stefano, F.; Conti, V.; Graziani, E.; Petroianni, A. Air pollution ultrafine particles: toxicity beyond the lung. European Review for Medical and Pharmacological Sciences 2010, 14(10), 809-821. 
8. De Jesus, A.L.; Rahman, M.M.; Mazaheri, M.; Thompson, H.; Knibbs, L.D.; Jeong, C.; et al. Ultrafine particles and $\mathrm{PM}_{2.5}$ in the air of cities around the world: Are they representative of each other?. Environment International 2019, 129, 118-135.

9. Gautam, S.; Yadav, A.; Tsai, C.J.; Kumar, P. A review on recent progress in observations, sources, classification and regulations of $\mathrm{PM}_{2.5}$ in Asian environments. Environmental Science and Pollution Research 2016, 23(21), 21165-21175.

10. Phairuang, W.; Hata, M.; Furuuchi, M. Influence of agricultural activities, forest fires and agro-industries on air quality in Thailand. Journal of Environmental Sciences 201752 , $85-97$.

11. Phairuang, W.; Suwattiga, P.; Chetiyanukornkul, T.; Hongtieab, S.; Limpaseni, W.; Ikemori, F.; et al. The influence of the open burning of agricultural biomass and forest fires in Thailand on the carbonaceous components in size-fractionated particles. Environmental Pollution 2019, 247, 238-247.

12. Cui, M.; Chen, Y.; Zheng, M.; Li, J.; Tang, J.; Han, Y.; et al. Emissions and characteristics of particulate matter from rainforest burning in the Southeast Asia. Atmospheric Environment 2018, 191, 194-204.

13. Vejpongsa, I., Suvachittanont, S., Klinklan, N., Thongyen, T., Veres, M., Szymanski, W.W. Deliberation between PM1 and PM2.5 as air quality indicators based on comprehensive characterization of urban aerosols in Bangkok, Thailand. Particuology 2017, 35, 1-9.

14. WHO. Review of evidence on health aspects of air pollution- REVIHAAP Project: Technical Report, World Health Organisation, Copenhagen, Denmark. 2013 Accessible 
at: http://www.euro.who.int/_data/assets/pdf_file/0004/193108/REVIHAAP-Finaltechnical-report-final-version.pdf (Accessed 28 August 2021).

15. Boongla, Y.; Chanonmuang, P.; Hata, M.; Furuuchi, M.; Phairuang, W. The characteristics of carbonaceous particles down to the nanoparticle range in Rangsit city in the Bangkok Metropolitan Region, Thailand. Environmental Pollution 2021, 272, 115940.

16. Phairuang, W.; Inerb, M.; Furuuchi, M.; Hata, M.; Tekasakul, S.; Tekasakul, P. Sizefractionated carbonaceous aerosols down to $\mathrm{PM}_{0.1}$ in southern Thailand: Local and longrange transport effects. Environmental Pollution 2020, 260, 114031.

17. Thuy, N.T.T.; Dung, N.T.; Sekiguchi, K.; Thuy, L.B.; Hien, N.T.T.; Yamaguchi, R. Mass concentrations and carbonaceous compositions of $\mathrm{PM}_{0.1}, \mathrm{PM}_{2.5}$, and $\mathrm{PM}_{10}$ at urban locations in Hanoi, Vietnam. Aerosol and Air Quality Research 2018, 18(7), 1591-1605.

18. Kumar, P.; Morawska, L.; Birmili, W.; Paasonen, P.; Hu, M.; Kulmala, M.; et al. Ultrafine particles in cities. Environment International 2014, 66, 1-10.

19. Venecek, M.A.; Yu, X.; Kleeman, M.J. Predicted ultrafine particulate matter source contribution across the continental United States during summertime air pollution events. Atmospheric Chemistry and Physics 2019, 19(14), 9399-9412.

20. Xue, J.; Xue, W.; Sowlat, M.H.; Sioutas, C.; Lolinco, A.; Hasson, A.; Kleeman, M.J. Seasonal and Annual Source Appointment of Carbonaceous Ultrafine Particulate Matter $\left(\mathrm{PM}_{0.1}\right)$ in Polluted California Cities. Environmental Science and Technology 2018, 53(1), 39-49. 
21. Taiwo, A.M.; Harrison, R.M.; Beddows, D.C.; Shi, Z. Source apportionment of single particles sampled at the industrially polluted town of Port Talbot, United Kingdom by ATOFMS. Atmospheric Environment 2014, 97, 155-165.

22. European Committee for Standardization: CEN/TS 16976:2016 Ambient air Determination of the particle number concentration of atmospheric aerosol.

23. Giechaskiel, B.; Lahde, T.; Suarez-Bertoa, R.; Clairotte, M.; Grigoratos, T.; Zardini, A.; Perujo. A.; Martini, G. Particle number measurements in the European legislation and future JRC activities. Combustion Engines 2018, 57.

24. Li, N.; Georas, S.; Alexis, N.; Fritz, P.; Xia, T.; Williams, M.A.; Horner, A.; Nel, A. A workgroup report on ultrafine particles (American Academy of Allergy, Asthma \& Immunology): Why ambient ultrafine and engineered nanoparticles should receive special attention for possible adverse health outcomes in human subjects. Journal of Allergy and Clinical Immunology 2016, 138(2), 386-396.

25. Zhao, T.; Hongtieab, S.; Hata, M.; Furuuchi, M.; Dong S.; Phairuang, W. et al. "Ambient nanoparticles characterization by East and Southeast Asia nanoparticle monitoring network." In Proceedings of the $9^{\text {th }}$ Asian Aerosol Conference, Kanazawa, Japan, pp. 2426. (2016).

26. Kim Oanh, N.T.; Permadi, D.A.; Hopke, P.K.; Smith, K.R.; Dong, N.P.; Dang, A.N. Annual emissions of air toxics emitted from crop residue open burning in Southeast Asia over the period of 2010-2015. Atmospheric Environment 2018, 187, 163-173.

27. Phairuang, W. Biomass Burning and Their Impacts on Air Quality in Thailand. In Biomass Burning in South and Southeast Asia (pp. 21-38). CRC Press 2021. 
28. Amin, M.; Putri, R.M.; Piriyakarnsakul, S.; Handika, R.A.; Ulla, A.; Phairuang, W. et al., Size-segregated particulate matter down to $\mathrm{PM}_{0.1}$ and carbon content during a haze episode in Sumatra Island, Indonesia. Proceedings of $18^{\text {th }}$ World Clean Air Congress (WCAC), September 23rd-27th, Istanbul, Turkey, 2019.

29. Putri, R.M.; Amin, M.; Suciari, T.F.; Faisal, M.A.F.; Auliani, R.; Ikemori, F. et al. Sitespecific variation in mass concentration and chemical components in ambient nanoparticles $\left(\mathrm{PM}_{0.1}\right)$ in North Sumatra Province-Indonesia. Atmospheric Pollution Research 2021, 101062.

30. Nghiem, T.D.; Nguyen, T.T.T.; Nguyen, T.T.H.; Ly, B.T.; Sekiguchi, K.; Yamaguchi, R.; Pham, C.T.; Ho, Q.B.; Duong, T.N. Chemical characterization and source apportionment of ambient nanoparticles: a case study in Hanoi, Vietnam. Environmental Science and Pollution Research 2020, 27, 30661-30672.

31. Ha, V.T.L.; Anh, V.D.; Hien, N.T.T.; Dung, N.T.; Shimada, Y.; Yoneda, M. Indoor and outdoor relationship of particles with different sizes at an apartment in Hanoi: mass concentration and respiratory dose estimation Vietnam Journal of Science and Technology 2020, 58 (6), 736-746.

32. Huyen, T.T.; Yamaguchi, R.; Kurotsuchi, Y.; Sekiguchi, K.; Dung, N.T.; Thuy, N.T.T.; Thuy, L.B. Characteristics of Chemical Components in Fine Particles $\left(\mathrm{PM}_{2.5}\right)$ and Ultrafine Particles $\left(\mathrm{PM}_{0.1}\right)$ in Hanoi, Vietnam: a Case Study in Two Seasons with Different Humidity. Water, Air, \& Soil Pollution 2021, 232(5), 1-21.

33. Thuy P.C.; Le, H.A.; Tuyen. L.H.; Dung., N.T. Size distribution and contribution of particles from rice straw open burning to the atmosphere in Hanoi. Vietnam Journal of Science and Technology 2020, 58 (5A), 94-104. 
34. Tran, T.D.; Nguyen, P.M.; Nghiem, D.T.; Le, T.H.; Tu, M.B.; Alleman, L.Y.; Nguyen, N.V. Assessment of Air Quality in School Environments in Hanoi, Vietnam: A Focus on Mass-Size Distribution and Elemental Composition of Indoor-Outdoor Ultrafine/Fine/Coarse Particles. Atmosphere 2020, 11(5), 519.

35. AQEG. Particulate Matter in the United Kingdom. Air Quality Expert Group, UK Department for Environment, Food and Rural Affairs, London, PB10580, 2005. Accessible at: http://ukair.defra.gov.uk/library/reports?report_id=269 (Accessed 11 August 2021).

36. Chen, S.C.; Tsai, C.J.; Chou, C.C.K.; Roam, G.D.; Cheng, S.S.; Wang, Y.N. Ultrafine particles at three different sampling locations in Taiwan. Atmospheric Environment 2010, 44(4), 533-540.

37. Zhu, C.S.; Chen, C.C.; Cao, J.J.; Tsai, C.J.; Chou Charles, C.K.; Liu, S.C.; Roam, G.D. Characterization of carbon fractions for atmospheric fine particles and nanoparticles in a highway tunnel. Atmospheric Environment 2010, 44, 2668-2673.

38. Hata, M.; Zhang, T.; Bao, L.; Otani, Y.; Bai, Y.; Furuuchi, M. Characteristics of the nanoparticles in a Road Tunnel. Aerosol and Air Quality Research 2012, 13(1), 194-200.

39. Ding, X.; Kong, L.; Du, C.; Zhanzakova, A.; Wang, L.; Fu, H. et al. Long-range and regional transported size-resolved atmospheric aerosols during summertime in urban Shanghai. Science of the Total Environment 2017, 583, 334-343.

40. Beddows, D.C.; Harrison, R.M. Comparison of average particle number emission factors for heavy and light duty vehicles derived from rolling chassis dynamometer and field studies. Atmospheric Environment 2008, 42(34), 7954-7966. 
41. Hata, M.; Chomanee, J.; Thongyen, T.; Bao, L.; Tekasakul, S.; Tekasakul, P.; Otani, Y.; Furuuchi, M. Characteristics of nanoparticles emitted from burning of biomass fuels. Journal of Environmental Sciences 2014, 26(9), 1913-1920.

42. Chomanee, J.; Tekasakul, S.; Tekasakul, P.; Furuuchi, M. Effect of irradiation energy and residence time on decomposition efficiency of polycyclic aromatic hydrocarbons (PAHs) from rubber wood combustion emission using soft X-rays. Chemosphere 2018, 210, 417423.

43. Phairuang, W.; Tekasakul, P.; Hata, M.; Tekasakul, S.; Chomanee, J.; Otani, Y.; Furuuchi, M. Estimation of air pollution from ribbed smoked sheet rubber in Thailand exports to Japan as a pre-product of tires. Atmospheric Pollution Research 2019, 10(2), 642-650.

44. Hsu, C.Y.; Chiang, H.C.; Chen, M.J.; Yang, T.T.; Wu, Y.S.; Chen, Y.C. Impacts of hazardous metals and PAHs in fine and coarse particles with long-range transports in Taipei City. Environmental Pollution 2019, 250, 934-943.

45. Janta, R.; Sekiguchi, K.; Yamaguchi, R.; Sopajaree, K.; Pongpiachan, S.; Chetiyanukornkul, T. Ambient $\mathrm{PM}_{2.5}$, polycyclic aromatic hydrocarbons and biomass burning tracer in Mae Sot District, western Thailand. Atmospheric Pollution Research 2020, 11(1), 27-39.

46. Holmes, N.S. A review of particle formation events and growth in the atmosphere in the various environments and discussion of mechanistic implications. Atmospheric Environment 2007, 41(10), 2183-2201. 
47. Rimnacova, D.; Zdímal, V.; Schwarz, J.; Smolík, J.; Rimnac, M. Atmospheric aerosols in suburb of Prague: the dynamics of particle size distributions. Atmospheric Research 2011, 101(3), 539-552.

48. Reche, C.; Querol, X.; Alastuey, A.; Viana, M.; Pey, J.; Moreno, T. et al. New considerations for PM, Black Carbon and particle number concentration for air quality monitoring across different European cities. Atmospheric Chemistry and Physics 2011, 11(13), 6207-6227.

49. Donaldson, K.; Stone, V.; Clouter, A.; Renwick, L.; MacNee, W. Ultrafine particles. Occupational and Environmental Medicine 2001, 58(3), 211-216.

50. Kreyling, W.G.; Semmler-Behnke, M.; Möller, W. Ultrafine particle lung interactions: does size matter?. Journal of Aerosol Medicine 2006, 19(1), 74-83.

51. Lanzinger, S.; Schneider, A.; Breitner, S.; Stafoggia, M.; Erzen, I.; Dostal, M. Associations between ultrafine and fine particles and mortality in five centrals European cities-Results from the UFIREG study. Environment International 2016, 88, 44-54.

52. WHO. Review of evidence on health aspects of air pollution-REVIHAAP Project: Technical Report, World Health Organisation, Copenhagen, Denmark 2013. Accessible at: $\quad$ http://www.euro.who.int/_data/assets/pdf_file/0004/193108/REVIHAAP-Finaltechnical-report-final-version.pdf (Accessed 22 August 2021).

53. HEI. Understanding the health effects of ambient ultrafine particles. HEI Perspectives 3. HEI Review Panel on Ultrafine Particles, Health Effects Institute, Boston, MA USA 2013. Accessible at: http://pubs.healtheffects.org/view.php?id=394. (Accessed 22 August 2021). 
54. Wunnapuk, K.; Pothirat, C.; Manokeaw, S.; Phetsuk, N.; Chaiwong, W.; Phuackchantuck, R.; Prapamontol, T. PM 10-related DNA damage, cytokinetic defects, and cell death in COPD patients from Chiang Dao district, Chiang Mai, Thailand. Environmental Science and Pollution Research 2019, 26(24), 25326-25340.

55. Zhang, L.; Morisaki, H.; Wei, Y.; Li, Z.; Yang, L.; Zhou, Q.; Toriba, A. Characteristics of air pollutants inside and outside a primary school classroom in Beijing and respiratory health impact on children. Environmental Pollution 2019, 255, 113147.

56. Han, F.; Guo, H.; Hu, J.; Zhang, J.; Ying, Q.; Zhang, H. Sources and health risks of ambient polycyclic aromatic hydrocarbons in China. Science of The Total Environment 2020, 698, 134229.

57. Deacqunita, D.; Harris, L.K.; Rekhadevi, V.P.; Ramesh, A. Tumor microsomal metabolism of the food toxicant, benzo(a)pyrene, in Apc mouse model of colon cancer. Tumour Biology 2012, 33(4), 1255-1260.

58. Guan, Y.; Chen, G.; Cheng, Z.; Yan, B.; Hou, L.A. Air pollutant emissions from straw open burning: A case study in Tianjin. Atmospheric Environment 2017, 171, 155-164.

59. Crippa, P.; Castruccio, S.; Archer-Nicholls, S.; Lebron, G.B.; Kuwata, M.; Thota, A. et al. Population exposure to hazardous air quality due to the 2015 fires in Equatorial Asia. Scientific Reports 2016, 6, 37074.

60. Chuang, M.T.; Fu, J.S.; Lee, C.T.; Lin, N.H.; Gao, Y.; Wang, S.H. et al. The simulation of long-range transport of biomass burning plume and short-range transport of anthropogenic pollutants to a mountain observatory in East Asia during the 7-SEAS/2010 Dongsha Experiment. Aerosol and Air Quality Research 2016, 16, 2933-2949. 
61. Tham, J.; Sarkar, S.; Jia, S.; Reid, J.S.; Mishra, S.; Sudiana I.M. et al. Impacts of peatforest smoke on urban $\mathrm{PM}_{2.5}$ in the Maritime Continent during 2012-2015: Carbonaceous profiles and indicators. Environmental Pollution 2019, 248, 496-505.

62. U.S. EPA. 1996. Air Quality Criteria for Particulate Matter (Final Report, 1996).

63. Samae, H.; Tekasakul, S.; Tekasakul, P.; Furuuchi, M. Emission factors of ultrafine particulate matter $(\mathrm{PM}<0.1 \mu \mathrm{m})$ and particle-bound polycyclic aromatic hydrocarbons from biomass combustion for source apportionment. Chemosphere 2021, 262, 127846.

64. Samae, H.; Tekasakul, S.; Tekasakul, P.; Phairuang, W.; Furuuchi, M.; Hongtieab, S. Particle-bound organic and elemental carbons for source identification of $\mathrm{PM}<0.1 \mu \mathrm{m}$ from biomass combustion. Journal of Environmental Sciences 2022, 113, 385-393.

65. Simões Amaral, S.; Andrade de Carvalho, J.; Martins Costa, M.; Pinheiro, C. Particulate matter emission factors for biomass combustion. Atmosphere 2016, 7(11), 141.

66. Hata, M.; Linfa, B.; Otani, Y.; Furuuchi, M. Performance evaluation of an Andersen cascade impactor with an additional stage for nanoparticle sampling. Aerosol and Air Quality Research 2012, 12(6), 1041-1048.

67. Tsai, C.J; Liu, C.N.; Hung, S.M.; Chen, S.C.; Uang, S.N.; Cheng, Y.S.; Zhou, Y. Novel active personal nanoparticle sampler for the exposure assessment of nanoparticles in workplaces. Environmental Science and Technology 2012, 46, 4546-4652.

68. Otani, Y.; Eryu, K.; Furuuchi, M.; Tajima, N.; Tekasakul, P. Inertial classification of nanoparticles with fibrous filters. Aerosol and Air Quality Research 2007, 7, 343-352.

69. Furuuchi, M.; Eryu, K.; Nagura, M.; Hata, M.; Kato, T.; Tajima, N. et al. Development and performance evaluation of air sampler with inertial filter for nanoparticle sampling. Aerosol and Air Quality Research 2010, 10, 185-192. 
70. Thongyen, T.; Hata, M.; Toriba, A.; Ikeda, T.; Koyama, H.; Otani, Y.; Furuuchi, M. Development of $\mathrm{PM}_{0.1}$ personal sampler for evaluation of personal exposure to aerosol nanoparticles Aerosol and Air Quality Research 2015, 15, 180-187.

71. Kumsanlas, N.; Piriyakarnsakul, S.; Sok, P.; Hongtieab, S.; Ikemori, F.; Szymanski, W. W. et al. A Cascade Air Sampler with Multi-nozzle Inertial Filters for $\mathrm{PM}_{0.1}$. Aerosol and Air Quality Research 2019, 19(8), 1666-1677.

72. Hering, S.V.; Friedlander, S.K.; Collins, J.J.; Richards, L.W. Design and evaluation of a new low-pressure impactor 2. Environmental Science and Technology 1979, 13 (2), 184188.

73. MSP Cooperation. MOUDI and NanoMOUDI impactors/MSP corporation 2021. Available at: www.mspcorp.com/aerosol-instruments/model-122-125-13-stage-moudiimpactors/ (Accessed 21 August 2021).

74. Hata, M.; Thongyen, T.; Bao, L.; Hoshino, A.; Otani, Y.; Ikeda, T.; Furuuchi, M. Development of a high-volume air sampler for nanoparticles. Environmental Science: Process and Impacts 2013, 15, 454-62.

75. Zhang, T.; Zhao, T.; Takahashi, H.; Hata, M.; Toriba, A.; Ikeda, T. et al., High volume air sampler for environmental nanoparticles using a sharp-cut inertial filter combined with an impactor. Measurement Science and Technology 2017, 28(2), 025801.

76. Kanabkaew, T.; Mekbungwan, P.; Raksakietisak, S.; Kanchanasut, K. Detection of PM 2.5 plume movement from IoT ground level monitoring data. Environmental Pollution 2019, 252, 543-552. 
77. Tariq, N.; Asim, M.; Al-Obeidat, F.; Zubair Farooqi, M.; Baker, T.; Hammoudeh, M.; Ghafir, I. The security of big data in fog-enabled IoT applications including blockchain: A survey. Sensors 2019, 19(8), 1788.

78. Zheng, T.; Bergin, M.H.; Johnson, K.K.; Tripathi, S.N.; Shirodkar, S.; Landis, D.E. Field evaluation of low-cost particulate matter sensors in high-and low-concentration environments. Atmospheric Measurement Techniques 2018. 11(8), 4823-4846. 